\title{
Evaluation of tooth number anomalies in a subpopulation of the North-East of Turkey
}

\author{
Muhammet Karadas $^{1}$, Mevlut Celikoglu², Mustafa Sadik Akdag ${ }^{3}$
}

Correspondence: Dr. Muhammet Karadas

Email: muhammet.2005@hotmail.com

\begin{abstract}
'Department of Restorative Dentistry, Faculty of Dentistry, Recep Tayyip Erdogan University, Rize, Turkiye, ²Department of Orthodontics, Faculty of Dentistry, Akdeniz University, Antalya, Turkiye,

${ }^{3}$ Department of Restorative Dentistry, Faculty of Dentistry, Karadeniz Technical University, Trabzon, Turkiye
\end{abstract}

\section{ABSTRACT}

Objective: The aim was to evaluate the prevalence and distribution of tooth number anomalies in a Turkish subpopulation. Materials and Methods: A population of 2722 patients (1532 females and 1190 males; mean age, $12.33 \pm 2.5$ years) was retrospectively examined to determine the prevalence and distribution of the hypodontia, oligodontia, and hyperdontia using panoramic radiographs. All permanent teeth were investigated except thirds molars and the data obtained were recorded as unilateral (left or right) or bilateral according to gender. Pearson's Chi-squared and Fisher exact tests were used for difference comparisons $(P<0.05)$. Results: Permanent tooth anomalies were found in at least $132(4.84 \%)$ of 2722 patients with no statistically difference between the genders, consists of $4.63 \%$ females and $5.12 \%$ males. Distribution of hyperdontia was statistically significant difference between genders, whereas distribution of hypodontia and oligodontia was no significant difference between genders. Hypodontia was the most frequently observed anomaly (3.67\%), followed by hyperdontia $(0.96 \%)$, and oligodontia $(0.21 \%)$. Oligodontia and hypodontia were more frequent in females (3.98\% and $0.26 \%$, respectively), whereas hyperdontia was more frequently observed in males $(1.68 \%)$. Maxillary lateral incisors were most common missing teeth $(2.27 \%)$, while the frequency of hyperdontia was most common in premolars. Conclusion: The prevalence of teeth number anomalies was $4.84 \%$ of dental patients. Maxillary lateral incisors were most common missing teeth, while the frequency of hyperdontia was most common in premolars.

Key words: Hyperdontia, hypodontia, oligodontia, prevalence

\section{INTRODUCTION}

Dental anomalies that may affect the size, form, position, and number of teeth are one of the anomalies of the human structure that result from certain genes in addition to some etiological events in the prenatal and postnatal periods. They may be localized to single tooth or including systemic conditions ${ }^{[1]}$ Abnormalities result from disturbances during initiation, morphodifferentiation stage of tooth development, apposition of hard dental tissues and during eruption of teeth. ${ }^{[2]}$

Developmental dental abnormalities comprising the number of teeth include missing teeth, and supernumerary teeth, also known as hyperdontia. Supernumerary teeth are those that develop in addition to normal complement as a result of excess dental lamina in the jaws, and the tooth or teeth that develop may be morphologically normal or abnormal. ${ }^{[3]}$ Developmentally missing teeth include hypodontia (absence of one to six teeth), oligodontia (absence of more than six teeth), and anodontia (complete absence of teeth) $\cdot^{[4]}$

The prevalence of hypodontia varies from $0.03 \%$ to $10.1 \%$ in various populations. ${ }^{[5]}$ In the permanent dentition, the most commonly missing teeth are the third molars, followed by either the mandibular second premolars or maxillary lateral incisors. ${ }^{[6]}$

\footnotetext{
How to cite this article: Karadas M, Celikoglu M, Akdag MS. Evaluation of tooth number anomalies in a subpopulation of the North-East of Turkey. Eur J Dent 2014;8:337-41.

Copyright @ 2014 Dental Investigations Society. DOI: $10.4103 / 1305-7456.137641$
} 
The absence can be unilateral or bilateral in same patients. ${ }^{[3]}$ Hypodontia of the first and second molars, lower canines and upper central incisors are considered relatively rare. ${ }^{[7]}$ Supernumerary teeth that are in excess of the normal are reported to vary from $0.15 \%$ to $3.9 \%$ in population ${ }^{[8]}$ and may present in either permanent or primary dentitions. ${ }^{[9]}$ A mesiodens that is most common a supernumerary tooth located in the anterior maxilla is between $0.15 \%$ and $1.9 \%$ in population..$^{[9,10]}$

Kazanci et al. ${ }^{[11]}$ investigated the prevalence of different developmental dental anomalies and reported that prevalence rates of hypodontia, oligodontia, and hyperdontia were $4.74 \%, 0.25 \%$, and $1.30 \%$, respectively. Sisman et al..$^{[12]}$ examined the prevalence and distribution of hypodontia in 2413 orthodontic patients, reported that the prevalence of hypodontia was $7.54 \%$. Furthermore, Altug-Atac and Erdem ${ }^{[13]}$ reported that prevalence of hypodontia, oligodontia, and hyperdontia (incisors and premolars) in orthodontic patients were $2.63 \%, 0.13 \%$, and $0.36 \%$, respectively. The prevalence and frequency of dental anomalies can provide considerable information for phylogenic and genetic studies and help understand variations within and between populations. ${ }^{[14]}$

According to oral disease such as dental caries and periodontal diseases, dental anomalies have low frequency, but it is very difficult for the treatment, because they can result in occlusion and esthetic problems, and give rise to the other oral complications. ${ }^{[15]}$ Since there have been no study published investigating the tooth number anomalies in the North-East region of Turkey. The aim of this study was to investigate the frequency and the distribution of dental number anomalies that could lead to function and aesthetic problems.

\section{MATERIALS AND METHODS}

This retrospective study was performed through an examination of panoramic radiographs of 2722 patients (1532 females and 1190 males) who applied to a variety of dental complaints, Faculty of Dentistry, Recep Tayyip Erdogan and Karadeniz Technical University. Ethical approval was not received for the retrospective study because patients were not exposed to additional radiation and not subjected to additional treatment. The patients (or parents) signed an informed consent agreeing to the use of the patients data. The mean age was $12.33 \pm 2.5$ years, ranging from 8 to 16 years.
Patients with a history of tooth extraction, developmental or hereditary disorders, bone defects, trauma, and fractures were excluded from study. All permanent teeth except thirds molars wereinvestigated using the panoramic radiographs previously taken with the same orthopanthomograph (OP200 D, Instrumentarium Dental F1-04300 Tuusula, Finland). The dental anomalies, including hypodontia (absence of one to six teeth on the panoramic radiograph), ${ }^{[4]}$ oligodontia (absence of more than six teeth), ${ }^{[4]}$ and hyperdontia (an increased number of teeth) ${ }^{[3]}$ were examined by one researcher who have at least 5 years of professional clinical experience, over about 20-week periods. During examination, second researcher was consulted when needed. Data obtained from panoramic radiographs were recorded according to gender and number of patients and also as unilateral (left or right) or bilateral in teeth with hypodontia.

\section{Statistical analysis}

Statistical analyses of data were performed using Statistical Package for Social Sciences program (SPSS, version 16.0, Chicago, IL, USA). Student's t-test was used to compare the chronological ages between male and female patients. The Pearson's Chi-square and Fisher exact tests were used to determine differences in the distribution of dental number anomalies between genders. It was tested at the $5 \%$ level of significance.

\section{RESULTS}

The study consisted of $56.2 \%$ female and $43.7 \%$ male patients with no statistically significant difference between the females $(12.09 \pm 2.5$ years $)$ and males (12.64 \pm 2.58 years) according to chronological ages [Table 1].

The distribution and frequency of tooth number anomalies according to gender is presented in Table 2. Permanent tooth number anomalies were found in at least 132 patients, consists of $4.63 \%$ for females and $5.12 \%$ for males. Hypodontia was the most frequently observed anomaly $(3.67 \%)$, followed by hyperdontia $(0.96 \%)$, and oligodontia $(0.21 \%)$.

Table 1: Descriptive data of the patients included to
the study
\begin{tabular}{lccc}
\hline Gender & $\boldsymbol{n}(\%)$ & Chronological age (years) & $\boldsymbol{P}$ \\
\hline Female & $1532(56.2)$ & $12.09 \pm 2.50$ & 0.001 \\
Male & $1190(43.7)$ & $12.64 \pm 2.58$ & \\
Total & $2722(100)$ & $12.33 \pm 2.55$ & \\
\hline
\end{tabular}


Distribution of hyperdontia statistically significantly differed between genders, whereas distribution of hypodontia and oligodontia did not. Oligodontia and hypodontia were more frequently in females $(3.98 \%$ and $0.26 \%$, respectively), whereas hyperdontia was more frequently in males $(1.68 \%)$.

Distribution of teeth with hypodontia is shown in Table 3 as unilateral or bilateral. Maxillary lateral incisors were most common missing teeth $(2.27 \%)$, followed by mandibular second premolars $(0.88 \%)$, maxillary second premolars and mandibular central incisors $(0.40 \%)$. The congenital missing teeth were more common in left side $(1.24 \%)$ than in right side $(0.91 \%)$, while they were more commonly distributed as unilateral $(2.16 \%)$ than bilaterally $(1.08 \%)$.

Distribution of supernumarary teeth in males $(20,1.68 \%)$ were more common than females $(6,0.39 \%)$, these difference between genders was statistically significant. Frequency of hyperdontia was most common in premolars with statistically significant difference between females $(0.26 \%)$ and males $(0.84 \%)$, followed by mesiodens $(0.22 \%)$, molars, and maxillary incisors [Table 4]. There were no statistically significant differences between the genders in terms of mesiodens and molar distribution.

The absence of maxillary lateral incisors in females $(39,2.54 \%)$ were more common than males $(23,1.93 \%)(P>0.05)$. Absence of maxillary lateral incisors were more common in left side than in right side, while they were equally distributed between bilateral $(1.13 \%, 31)$ and unilateral $(1.13 \%, 31)$. Difference between genders according to unilateral or bilateral maxillary lateral incisors was not statistically significant [Table 5].

\section{DISCUSSION}

Congenital or developmental dental anomalies are related to genetic and environmental factors, may be also genetically determined and can be associated with specific syndromes. ${ }^{[16]}$ Epidemiological studies might helpful in not only discovering the genetic and environmental causes for dental anomalies, but also establishing a basic awareness among dentists. ${ }^{[17]}$ Several studies in the last 15 years have focused on dental anomalies among orthodontic populations and these studies reported different prevalence values compared with former data derived from general populations. ${ }^{[11,18,19]}$
Kazanci et al. ${ }^{[11]}$ investigated the prevalence of dental anomalies in 3165 Turkish orthodontic patients ranging in age from 9 to 25 and reported that prevalence of tooth number anomalies were $5.84 \%$ (in 185 patients). Altug-Atac and Erdem ${ }^{[13]}$ reported that tooth number anomalies were in 95 of 3043 Turkish orthodontic patients (3.12\%). In $132(4.84 \%)$ of 2722 dental patients in this study, at least one permanent tooth number anomaly was determined. When compared in terms of prevalence of hypodontia, oligodontia, and hyperdontia, our results were lower than the findings of Kazanci et al., ${ }^{[1]]}$ and higher than the findings of Altug-Atac and Erdem. ${ }^{[13]}$ On the other hand, Gupta

\begin{tabular}{|c|c|c|c|c|}
\hline $\begin{array}{l}\text { Dental } \\
\text { anomalies }\end{array}$ & $\begin{array}{c}\text { Female (\%) } \\
n=1532\end{array}$ & $\begin{array}{c}\text { Male (\%) } \\
n=1190\end{array}$ & $P$ & $\begin{array}{c}\text { Total }(\%) \\
n=2722\end{array}$ \\
\hline Hypodontia & $61(3.98)$ & $39(3.27)$ & 0.33 & $100(3.67)$ \\
\hline Oligodontia & $4(0.26)$ & $2(0.16)$ & $0.93^{*}$ & $6(0.21)$ \\
\hline Hyperdontia & $6(0.39)$ & $20(1.68)$ & 0.00 & $26(0.96)$ \\
\hline Total & $71(4.63)$ & $61(5.12)$ & 0.553 & $132(4.84)$ \\
\hline
\end{tabular}

\begin{tabular}{lcccc} 
Table 3: Distribution of teeth with hypodontia \\
\hline Teeth & Left & Right & $\begin{array}{c}\text { Left+ } \\
\text { right }\end{array}$ & $\begin{array}{c}\text { Total } \\
\text { (\%) }\end{array}$ \\
\hline Maxillary lateral incisors & 19 & 12 & 31 & $62(2.27)$ \\
$\begin{array}{l}\text { Maxillary second premolars } \\
\text { Mandibular second }\end{array}$ & 6 & 4 & 1 & $11(0.40)$ \\
premolars & 9 & 7 & 8 & $24(0.88)$ \\
Mandibular central incisors & 0 & 2 & 9 & $11(0.40)$ \\
Total (\%) & $34(1.24)$ & $25(0.91)$ & $49(1.80)$ & $108(3.96)$ \\
\hline
\end{tabular}

\begin{tabular}{|c|c|c|c|c|}
\hline Teeth & Female (\%) & Male (\%) & $P$ & Total (\%) \\
\hline Premolars & $4(0.26)$ & $10(0.84)$ & 0.036 & $14(0.51)$ \\
\hline Mesiodens & $1(0.06)$ & $5(0.42)$ & $0.121^{*}$ & $6(0.22)$ \\
\hline Maxillary incisors & $0(0.0)$ & $1(0.08)$ & - & $1(0.03)$ \\
\hline Molars & $1(0.06)$ & $4(0.33)$ & $0.237^{*}$ & $5(0.18)$ \\
\hline Total (\%) & $6(0.39)$ & $20(1.68)$ & & $26(0.95)$ \\
\hline
\end{tabular}

\begin{tabular}{|c|c|c|c|c|}
\hline Pattern & $\begin{array}{c}\text { Female } \\
(n=1532)(\%)\end{array}$ & $\begin{array}{c}\text { Male } \\
(n=1190)(\%)\end{array}$ & $\begin{array}{c}\text { Total } \\
(n=2722)(\%)\end{array}$ & $P$ \\
\hline 12 & $5(0.32)$ & $7(0.58)$ & $12(0.44)$ & 0.308 \\
\hline 22 & $13(0.84)$ & $6(0.50)$ & $19(0.69)$ & 0.285 \\
\hline $12-22$ & $21(1.37)$ & $10(0.84)$ & $31(1.13)$ & 0.196 \\
\hline Total & $39(2.54)$ & $23(1.93)$ & $62(2.27)$ & 0.289 \\
\hline
\end{tabular}


et al. ${ }^{[20]}$ investigated the prevalence and distribution of dental anomalies in 1123 Indian outpatient subjects and reported that the prevalence of hypodontia $(47,4.19 \%)$, oligodontia $(4,0.36)$, hyperdontia $(27,2.40 \%)$ were higher than our findings. These conflicting results can be explained by local environmental influences, racial differences, nutrition, selected age groups, and different sample size.

Ortodontic patients have a greater tendency for dental anomalies, because patients probably were referred to orthodontic clinics by other dental health professionals. ${ }^{[17,21]}$ Trakiniene et al. ${ }^{[22]}$ Gábris et al. ${ }^{[23]}$ and Sisman et al. ${ }^{[12]}$ had reported that the prevalence of hypodontia in orthodontic patients were $17.11 \%, 14,69 \%$, and $7.54 \%$, respectively. The prevalence of hypodontia was reported widely in different parts of the world. ${ }^{[12,24-26]}$ This study reported a hypodontia prevalence of $3.67 \%$ in dental patients with no statistically significant difference between the genders, this ratio was consistent with previously reported prevalence rates $(3-10 \%) \cdot{ }^{[3]}$ The general prevalence of hypodontia was higher in females than males according to results obtained. Some studies showed that prevalence of hypodontia was no differences between males and females, ${ }^{[27,28]}$ but others reported a higher incidence in females than in males. ${ }^{[2,30]}$ In this study, the prevalence of hypodontia was higher in females $(3.98 \%)$ than in males $(3.27 \%)$.

The types of congenital missing teeth vary in different ethnic groups. Previous studies reported that the mandibular second premolars were most commonly missing teeth, ${ }^{[21,31]}$ while others showed that maxillary lateral incisor was the most prevalence missing tooth incisors in individuals with agenesis of only one or two teeth, ${ }^{[6,11,12]}$ which is in accordance with our findings. The prevalence of missing maxillary lateral incisors was reported as $1.74 \%^{[13]}$ and $2.62 \%{ }^{[11]}$ in previous studies. In bilaterally missing teeth, symmetric hypodontia was more predominant than asymmetric hypodontia, which is in accordance with previous reports. ${ }^{[6,28]}$ Kazanci et al. ${ }^{[11]}$ reported that the prevalence of missing maxillary lateral incisors were higher in unilaterally than in bilaterally. On the other hand, Altug-Atac and Erdem ${ }^{[13]}$ reported that the prevalence of missing maxillary lateral incisors were higher in bilaterally than in unilaterally. In our study, the prevalence of missing maxillary lateral incisors was similar between unilaterally and bilaterally.
Oligodontia can occur as an isolated case or as part of a syndrome, such as ectodermal dysplasia. Kazanci et al..$^{[11]}$ and Rølling and Poulsen ${ }^{[32]}$ found that oligodontia was more common in girls than boys, which is in accordance with our findings, but Altug-Atac and Erdem ${ }^{[13]}$ reported that oligodontia was more frequent in males.

Zhu et al. ${ }^{[33]}$ reported the prevalence of supernumerary teeth by race; the prevalence among the white population ranged from $1 \%$ to $3 \%$, which is consistent with the findings of Kazanci et al. ${ }^{[11]}(1.30 \%)$, while Altug-Atac and Erdem ${ }^{[13]}$ reported that the prevalence of hyperdontia was $0.36 \%$. In this study, the prevalence of hyperdontia was $0.96 \%$, the premolars were most common type of hyperdontia $(0.51 \%)$, which is in accordance with the findings of Kazanci et al. ${ }^{[11]}(0.31 \%)$, followed by mesiodens, molars, and maxillary incisors. Kazanci et al. ${ }^{[11]}$ and Rajab and Hamdan ${ }^{[34]}$ reported that the prevalence of hyperdontia was higher in males than females, which is consistent with our results. If supernumerary teeth erupt, they can cause malalignment of the normal dentition. According to their observations, early extraction was more beneficial, but further clinical and radiological follow-up is indicated in some cases that remain in jaws of supernumerary teeth. ${ }^{[35]}$ Dental anomalies should be thoroughly investigated during diagnosis and carefully considered treatment planning, because dental anomalies can complicate orthodontic treatment.

\section{CONCLUSIONS}

In this study, permanent tooth number anomalies were found in at least 132 patients $(4.84 \%)$, consists of $4.63 \%$ females and $5.12 \%$ males. Hypodontia were most frequent anomaly, followed by hyperdontia and oligodontia. Oligodontia and hypodontia were more frequent in females, whereas hyperdontia was more frequently in males. Maxillary lateral incisors were most common missing teeth, followed by mandibular second premolars, maxillary second premolars, and mandibular central incisors. Frequency of hyperdontia was most common in premolars with statistically significant difference between females and males.

\section{REFERENCES}

1. Winter GB, Brook AH. Enamel hypoplasia and anomalies of the enamel. Dent Clin North Am 1975;19:3-24.

2. Colak H, Uzgur R, Tan E, Hamidi MM, Turkal M, Colak T. Investigation of prevalence and characteristics of mesiodens in a 
non-syndromic 11256 dental outpatients. Eur Rev Med Pharmacol Sci 2013;17:2684-9.

3. White SC, Pharoah MJ. Oral Radiology Principles and Interpretation. $6^{\text {th }}$ ed. St. Louis: Mosby; 2009. p. 310-65.

4. Arte S. Phenotypic and genotypic features of familial hypodontia. Thesis, University of Helsinki; 2001.

5. Mattheeuws N, Dermaut L, Martens G. Has hypodontia increased in Caucasians during the $20^{\text {th }}$ century? A meta-analysis. Eur J Orthod 2004;26:99-103.

6. Muller TP, Hill IN, Peterson AC, Blayney JR. A survey of congenitally missing permanent teeth. J Am Dent Assoc 1970;81:101-7.

7. Dermaut LR, Goeffers KR, De Smit AA. Prevalence of tooth agenesis correlated with jaw relationship and dental crowding. Am J Orthod Dentofacial Orthop 1986;90:204-10.

8. Brabant H. Comparison of the characteristics and anomalies of the deciduous and the permanent dentition. J Dent Res 1967;46:897-902.

9. Sykaras SN. Mesiodens in primary and permanent dentitions. Report of a case. Oral Surg Oral Med Oral Pathol 1975;39:870-4.

10. Primosch RE. Anterior supernumerary teeth-assessment and surgical intervention in children. Pediatr Dent 1981;3:204-15.

11. Kazanci F, Celikoglu M, Miloglu O, Ceylan I, Kamak H. Frequency and distribution of developmental anomalies in the permanent teeth of a Turkish orthodontic patient population. J Dent Sci 2011;6:82-9.

12. Sisman Y, Uysal T, Gelgor IE. Hypodontia. Does the prevalence and distribution pattern differ in orthodontic patients? Eur J Dent 2007;1:167-73

13. Altug-Atac AT, Erdem D. Prevalence and distribution of dental anomalies in orthodontic patients. Am J Orthod Dentofacial Orthop 2007;131:510-4.

14. Jukic J, Skrinjaric I, Glavina D, Ulovec Z. The prevalence of oral and dental anomalies in children with developmental disturbances. Acta Stomatol Croat 2002;36:79-83.

15. Kathariya MD, Nikam AP, Chopra K, Patil NN, Raheja H, Kathariya R. Prevalence of dental anomalies among school going children in India. J Int Oral Health 2013;5:10-4.

16. Hattab FN, Yassin OM, al-Nimri KS. Talon cusp-clinical significance and management: Case reports. Quintessence Int 1995;26:115-20.

17. Hua F, He H, Ngan P, Bouzid W. Prevalence of peg-shaped maxillary permanent lateral incisors: A meta-analysis. Am J Orthod Dentofacial Orthop 2013;144:97-109.

18. Thongudomporn U, Freer TJ. Prevalence of dental anomalies in orthodontic patients. Aust Dent J 1998;43:395-8.

19. Basdra EK, Kiokpasoglou M, Stellzig A. The Class II Division 2 craniofacial type is associated with numerous congenital tooth anomalies. Eur J Orthod 2000;22:529-35.

20. Gupta SK, Saxena P, Jain S, Jain D. Prevalence and distribution of selected developmental dental anomalies in an Indian population. J Oral Sci 2011;53:231-8.
21. Kim YH. Investigation of hypodontia as clinically related dental anomaly: Prevalence and characteristics. ISRN Dent 2011;2011:246135.

22. Trakiniene $G$, Ryliškyte $M$, Kiaušaite $A$. Prevalence of teeth number anomalies in orthodontic patients. Stomatologija 2013;15:47-53.

23. Gábris K, Fábián G, Kaán M, Rózsa N, Tarján I. Prevalence of hypodontia and hyperdontia in paedodontic and orthodontic patients in Budapest. Community Dent Health 2006;23:80-2.

24. Rosenzweig KA, Garbarski D. Numerical aberrations in the permanent teeth of grade school children in Jerusalem. Am J Phys Anthropol 1965;23:277-83.

25. Davis PJ. Hypodontia and hyperdontia of permanent teeth in Hong Kong schoolchildren. Community Dent Oral Epidemiol 1987;15:218-20.

26. al-Emran S. Prevalence of hypodontia and developmental malformation of permanent teeth in Saudi Arabian schoolchildren. Br J Orthod 1990;17:115-8.

27. Lynham A. Panoramic radiographic survey of hypodontia in Australian Defence Force recruits. Aust Dent J 1990;35:19-22.

28. Rølling S. Hypodontia of permanent teeth in Danish schoolchildren Scand J Dent Res 1980;88:365-9.

29. Fekonja A. Hypodontia in orthodontically treated children. Eur J Orthod 2005;27:457-60.

30. Endo T, Ozoe R, Kubota M, Akiyama M, Shimooka S. A survey of hypodontia in Japanese orthodontic patients. Am J Orthod Dentofacial Orthop 2006;129:29-35.

31. Nordgarden H, Jensen JL, Storhaug K. Reported prevalence of congenitally missing teeth in two Norwegian counties. Community Dent Health 2002;19:258-61.

32. Rølling S, Poulsen S. Oligodontia in Danish schoolchildren. Acta Odontol Scand 2001;59:111-2.

33. Zhu JF, Marcushamer M, King DL, Henry RJ. Supernumerary and congenitally absent teeth: A literature review. J Clin Pediatr Dent 1996;20:87-95.

34. Rajab LD, Hamdan MA. Supernumerary teeth: Review of the literature and a survey of 152 cases. Int J Paediatr Dent 2002;12:244-54.

35. Van Buggenhout G, Bailleul-Forestier I. Mesiodens. Eur J Med Genet 2008;51:178-81.

\begin{tabular}{|l|l|}
\hline \multicolumn{2}{|c|}{ Access this article online } \\
\hline Quick Response Code: & Website: \\
& www.eurjdent.com \\
& \\
&
\end{tabular}

